\title{
Creation of a Database on Failures of Recycled Household Appliances as a Way to Improve Product Reliability
}

\author{
Irina Reznikova ${ }^{1, *}$ \\ ${ }^{I}$ Institute of Engineering and Environmental Safety, Togliatti State University, Togliatti 445020, Russian Federation \\ "Corresponding author. Email: ivreznikova@yandex.ru
}

\begin{abstract}
Improving product reliability is one of the main challenges for manufacturers. The capabilities of modern technology make it possible to create and analyze information about waste. Information on failures at various stages of the product life cycle, including at the disposal stage, allows the manufacturer to make changes in the design, technological processes and work organization. This paper tackles the issues of the creation of a database on failures of recycled household appliances with a purpose of improving the product reliability. This information is used in the pathways towards the creation of smart homes and providing a two-way flow of information between the producers of appliances and the customers. All of these leads to the digitalization of the economy and using modern information and communication technologies in households.
\end{abstract}

Keywords: Reliability, recycling, risk assessment, database, smart home systems, digital homes, sustainability.

\section{INTRODUCTION}

Nowadays, in the Russian Federation the current ISO 14001-2015 standard requires the manufacturer to determine the environmental aspects associated with the organization's activities from the design and development stage of processes, products and services to the disposal stage. Many manufacturers are currently working with this approach. However, manufacturers often do not know how much information they need is not being used $[1,2]$.

As an example, consider the actions of a certain manufacturer engaged in the manufacture of household appliances. Today, household appliances are becoming "smarter" and more user-friendly. And, as a consequence of this, more complicated [3]. The release of household appliances begins, of course, with marketing research: a manufacturer studies the preferences and preferences of its potential consumers using various methods, for example, sociological surveys, sales analysis and others. By researching the preferences of potential consumers, the manufacturer receives invaluable information about what consumer properties the manufactured equipment should have. Thus, the manufacturer gradually forms a rather extensive database, information from which he can use and, of course, successfully uses not only to improve the design and ergonomic characteristics of the products. The assignment of a unique number to each unit of manufactured products nowadays also does not surprise anyone [4].

Let us look at the product life cycle diagram. In addition to the stages discussed above, the diagram includes a "disposal" stage. By analyzing the information obtained at this stage, the manufacturer can also obtain very useful information. Therefore, we consider a certain manufacturer engaged in the production of household appliances - teapots, irons, mixers, etc. Each product is assigned a unique identification number. Each product has a so-called "warranty period", the duration of which depends on many factors. However, most often this period is 3 years. Repair of household appliances during the period of the manufacturer's warranty is carried out, as a rule, in workshops that have an appropriate license. But the life of a product is often not limited only by the warranty period. The information received by the manufacturer from the workshops allows the creation and use of another database - on failures and malfunctions. Such information is of great interest to the manufacturer, since it allows you to eliminate the causes that caused failures and malfunctions using design, technological and other changes [5].

Finally, the final stage of the product life cycle begins - recycling. The process of recycling household appliances is not yet as efficient as, say, the process of recycling cars. In order to increase sales, sellers of household appliances sometimes resort to such a method of attracting customers as "exchanging old appliances for new ones." In this case, buyers are reduced in the cost of 
the purchased equipment. Representatives of the retail network send the household appliances obtained in this way from the buyer to charities, sell them through thrift stores, or simply send them to a landfill. Consumers who do not participate in technology "exchange" programs do the same. The manufacturer, thus, loses information that is very important for himself. If information about the recyclable products comes to the manufacturer, then the manufacturer will have another set of data - about what failures and malfunctions and after what period of time appear on the product. So, the manufacturer generates several databases, information from which can be used for troubleshooting. The first base is formed at the stage of product operation, the other at the final stage of the product life cycle. Obtaining information and malfunctions of the equipment that is sent for disposal will enable the manufacturer to correct the deficiencies identified in the equipment.

\section{RESEARCH BACKGROUND}

The process of creating a database on malfunctions of equipment sent for disposal based on the GOST standards $[6,7,8]$ may look like this (Figure 1).

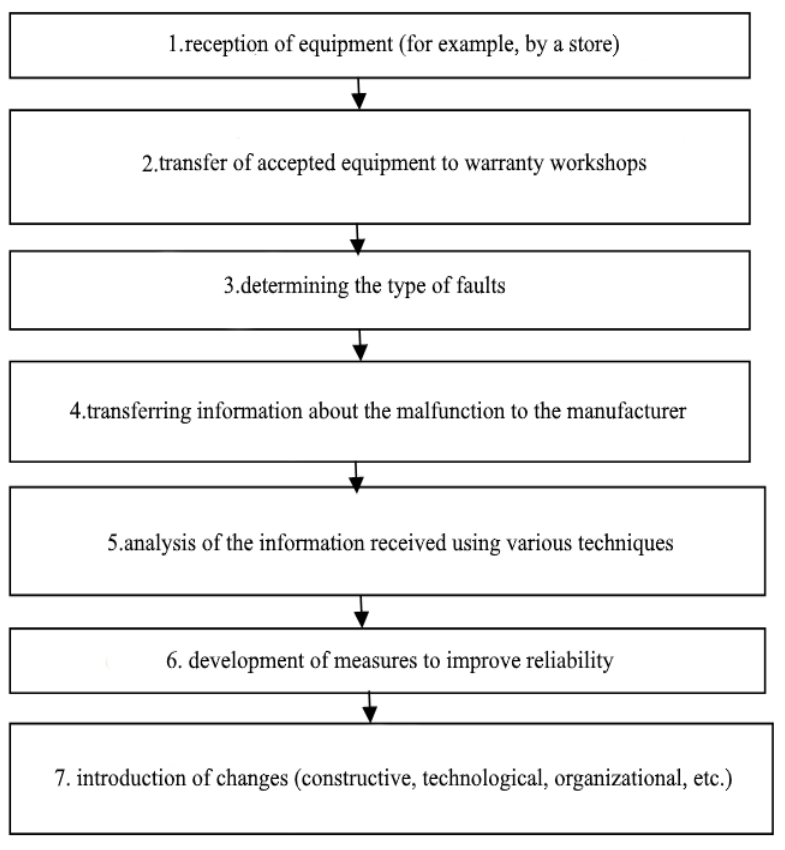

Figure 1 The process of creating a database on malfunctions of equipment

Thus, the manufacturer has the opportunity to obtain information about product defects., Detected not only during the warranty period, but also in the so-called postwarranty period.
Let us consider in more detail some of the stages of creation and operation of the database on malfunctions of equipment sent for disposal. Acceptance of equipment is carried out, for example, by a store. When accepting the equipment, the representative of the retail network fixes a unique identification number, which allows you to set the production date, up to the shift number. This information will allow you to establish a list of equipment and tooling involved in the production process. Then, during the analysis, the manufacturer will have the opportunity (if necessary) to adjust the functioning of the equipment. The stage of analysis of the information received by the manufacturer seems to be very important. The causes of malfunctions can be deficiencies in the operation of the equipment, and problems associated with the materials used, and deficiencies in the organization of production processes, as well as some others. The manufacturer should conduct such an analysis as thoroughly as possible, using various methods.

Let us make an attempt to establish exactly what methods of risk analysis can be used. As you know, the process of risk analysis consists of several stages: Risk identification - Risk analysis - Comparative risk assessment.

The risk identification is the first step in risk analysis and therefore its importance cannot be underestimated. The identification of risks in the analysis of failures of household appliances by the manufacturer can be carried out using methods such as "Brainstorming", "Delphi Method", "Checklists", "Causal analysis" and some others. It should be borne in mind that when choosing an identification method, one should take into account the possibility or impossibility of applying one or another method.

Similarly, at the stage of risk analysis, both the methods mentioned above and some others can be used. For example, "Analysis of the types and causes of consequences", "Structured Scenario Analysis by the What If?" (SWIFT) method, "Hazard and Operability Study" and some others.

The third stage of risk analysis (Comparative risk assessment), of course, also requires the use of different methods. The complexity of the implementation of the risk analysis process lies, among other things, in the correct choice of the analysis methodology at each of the stages. The factors influencing the choice of the method are the level of complexity of the method, the presence or absence of resources and capabilities, the possibility of obtaining quantitative output data, and some others. One of these factors is the factor "the ability to obtain quantitative outputs." It is quantitative data that are preferable for analysis. However, for a number of 
reasons, it is not always possible to obtain quantitative data.

The performed risk analysis is a solution to one of the tasks when creating a reliability management system. It is known that the creation of a reliability management system contributes to solving such problems as achieving the required level of product reliability, ensuring product reliability, improving product reliability, and some others. Thus, carrying out the analysis of equipment failures at the manufacturer using various methods is an element of the reliability management system.

\section{SCHEME FOR DATABASE CREATION}

It is known that the list of measures for reliability management is quite extensive and includes, for example, the allocation of resources, advanced training, incentives and motivation of enterprise personnel involved in reliability management activities [9]. Thus, the proposed scheme for creating a database on malfunctions of household appliances sent for recycling can consist of the following stages:

1.Receiving equipment (for example, by a shop)

2. Transfer of the accepted technique to the warranty workshops

3.Determining the type of malfunction or malfunctions

4.Transferring information about identified faults to the manufacturer

5.Analysis of the information received using various techniques

6. Development of measures to improve the reliability of equipment

7. Making changes (constructive, technological, organizational)

\section{Analysis of the effectiveness of changes}

The stage of analyzing the effectiveness of the changes made seems to be very important in the proposed procedure, since it is very important for the manufacturer to understand whether the measures taken lead to the achievement of the desired result [10].

Obviously, in the absence of such a result, the manufacturer needs to develop a new action plan to improve the reliability of its products. An example of the procedure for creating a database on malfunctions of equipment sent for disposal is shown in Figure 2 above.

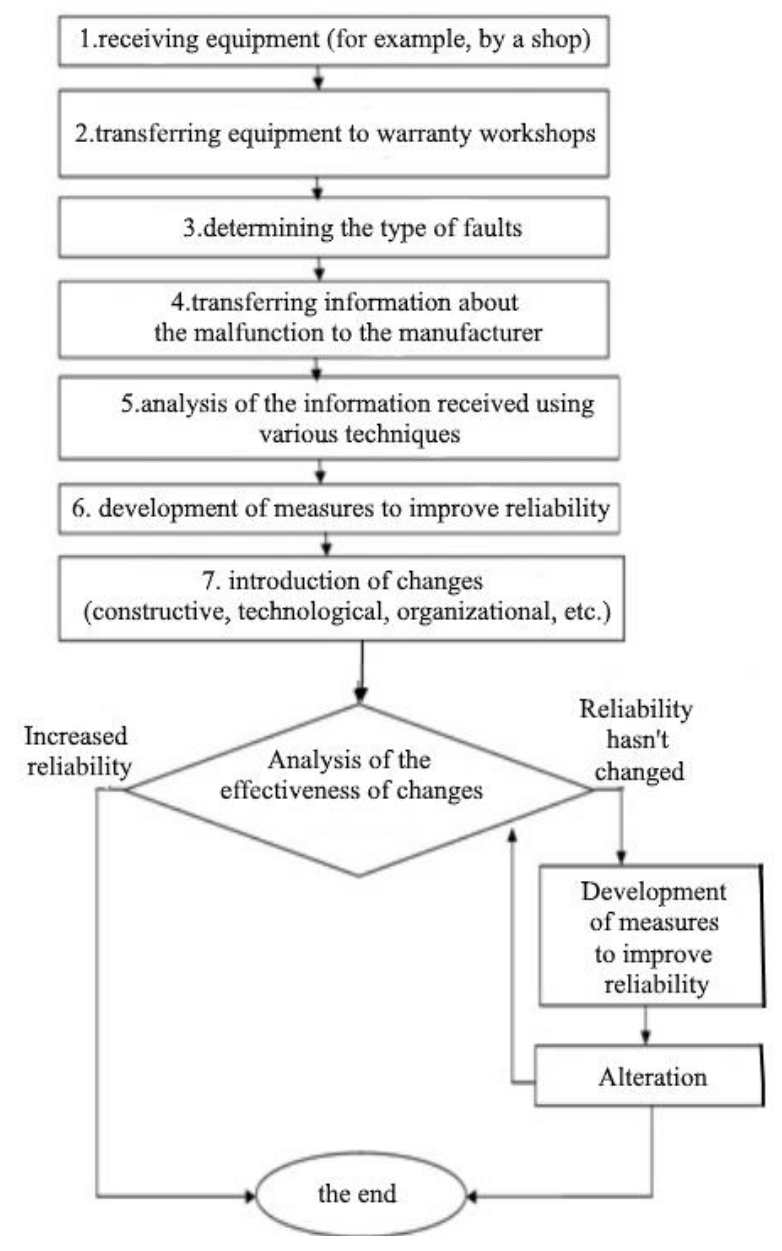

Figure 2 An example of the procedure for creating a database on malfunctions of equipment

When analyzing the effectiveness of the implemented measures to improve the reliability of products, the manufacturer needs to develop indicators of the effectiveness of the measures. This indicator can be, for example, the consumer loyalty ratio or the consumer loyalty index. Usually, manufacturers define this index in a fairly simple way - by conducting consumer surveys. The question of the questionnaire offered to consumers is usually simple: "What is the probability that you will recommend the product to your acquaintances, friends, colleagues?" The assessment is made, as a rule, on a 10-point scale. It should be noted that the answers to this question may not always reflect the real state of affairs. Answering this question, the consumer cannot always give a truthful answer. In this case, the manufacturer will receive distorted information.

If the manufacturer forms a database on the failures of the recycled equipment, he will be able to carry out, among other things, an analysis of consumer loyalty to his products. Figure 3 shows the product life cycle. 


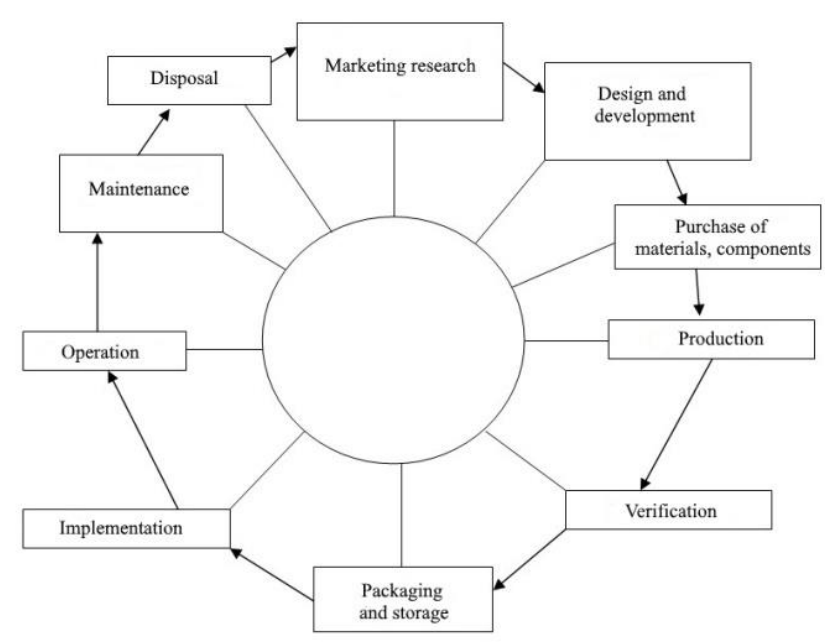

Figure 3 Product life cycle

In general, the product life cycle consists of the following stages:

1. Marketing research

2.Design and development

3.Purchase of materials, components

4.Production

5.Verification

6.Packaging and storage

7.Implementation

8.Operation

9.Maintenance

10.Disposal

At each of these stages, the manufacturer can create databases on household appliances failures. At the stage of marketing research, this may be information about failures of similar products.

In addition, failure databases can also be generated at the design, procurement and production stages. At the verification stage, it is quite easy to form a database of failures. Analysis of information from various databases would become the prerequisite that would allow the producer to manage the reliability of products.

\section{CONCLUSIONS}

Overall, in order to create a viable scheme for the smart house that would function two-ways, several approaches can and should be used. Our results show that any manufacturer of the household appliances would have several databases, the use of which will help him to improve the reliability of products.
Moreover, it is obvious that some of the data from the database on household appliances failures during the socalled "warranty period" will coincide with data on household appliances failures during product disposal. However, some of the information will not match. And this information will also be very important for the manufacturer. Thence, solutions need to be introduced in order to be capable of retrieving this information and putting it to good use. This might constitute the scope of the follow-up research on this topic.

\section{REFERENCES}

[1] M. Lagunova, Concerning the relevance of ISO 14001 adoption in enterprises. MATEC Web of Conferences $311 \quad$ (2020), 0202. DOI: https://doi.org/10.1051/matecconf/202031102022

[2] S. Ahmad, K. Wong, M. Tseng, W. Wong, Sustainable product design and development: A review of tools, applications and research prospects. Resources, Conservation and Recycling, 132 (2018), 49-61. DOI: https://doi.org/10.1016/j.resconrec.2018.01.020

[3] W. Strielkowski, D. Streimikiene, A. Fomina, E. Semenova, Internet of energy (IoE) and high-renewables electricity system market design, Energies 12(24) (2019) 4790. DOI: https://doi.org/10.3390/en12244790

[4] W. Zhu, X. Fan, Y. Zhang, Applications and research trends of digital human models in the manufacturing industry. Virtual reality \& intelligent hardware, 1(6) (2019), 558-579. DOI: https://doi.org/10.1016/j.vrih.2019.09.005

[5] S. Mourtzis, Simulation in the design and operation of manufacturing systems: state of the art and new trends. International Journal of Production Research, 58(7) (2020), 1927-1949. DOI: https://doi.org/10.1080/00207543.2019.1636321

[6] GOST P 27.001-2009 Dependability in technics. Dependability management system. Basic principles. http://docs.cntd.ru/document/1200078693 Accessed on 27 Dec 2020

[7] GOST 27.003-2016 Industrial product dependability. Contents and general rules for specifying. http://docs.cntd.ru/document/1200144951 Accessed on 12 Dec 2020

[8] GOST P ISO 31010-2011 Risk management. Risk assessment methods. http://docs.cntd.ru/document/gostr-iso-mek-31010-2011 Accessed on 27 Dec 2020 
[9] P. Saeidi, S. Saeidi, S. Sofian, S. Saeidi, M. Nilashi, A. Mardani, The impact of enterprise risk management on competitive advantage by moderating role of information technology. Computer Standards \& Interfaces, $63 \quad$ (2019), 67-82. DOI: https://doi.org/10.1016/j.csi.2018.11.009

[10] G. Yadav, S. Luthra, S. Jakhar, S. Mangla, D. RaiA framework to overcome sustainable supply chain challenges through solution measures of industry 4.0 and circular economy: An automotive case. Journal of Cleaner Production, 254 (2020), 120112. DOI: https://doi.org/10.1016/j.jclepro.2020.120112 